\title{
Staff emotional reactions and experiences towards challenging behaviour:
}

\section{An interview study}

\author{
Greet Lambrechts \& Bea Maes
}

\author{
Authors' details \\ Dr. Greet Lambrechts* \\ Post-Doctoral researcher \\ Katholieke Universiteit Leuven \\ Faculty of Psychology and Educational Sciences \\ Leopold Vanderkelenstraat 32, P.O. Box 3765 \\ B-3000 Leuven
}

BELGIUM

tel: 0032 16326278, fax: 003216325933

mail: greet.lambrechts@ppw.kuleuven.be

Prof. Dr. Bea Maes

Full Professor

Katholieke Universiteit Leuven

Faculty of psychology and educational sciences

Leopold Vanderkelenstraat 32, P.O. Box 3765

B-3000 Leuven

\section{BELGIUM}

tel: 003216326224 , fax: 003216325933

mail: bea.maes@ppw.kuleuven.be

$\left({ }^{*}\right)$ Please send correspondence to the first author

Notice: this is the author's version of a work that was accepted for publication in International Journal of Developmental Disabilities. Changes resulting from the publishing process, such as peer review, editing, corrections, structural formatting, and other quality control mechanisms may not be reflected in this document. Changes may have been made to this work since it was submitted for publication. A definitive version was subsequently published in International Journal of Developmental Disabilities (2012), 58(2), 95-110. DOI $10.1179 / 2047387711 Y .0000000009$ 
Staff emotional reactions and experiences towards challenging behaviour

\section{SUMMARY}

More and more attention is given to the psychological effects of challenging behaviour on others. Staff members' emotional reactions and experiences are important variables in this context and need to be studied using direct measurement of staff exposure to challenging behaviours. In this study, 12 staff members were confronted with video recordings of their own behaviour in situations in which a client was showing challenging behaviour. They were interviewed about their emotions and emotional experiences. Next to positive and negative emotions, staff members often mentioned the importance of the help they received from their colleagues. Some emotions were linked to the frequency of the challenging behaviour and often staff members referred to thoughts, questions and doubts that were playing in their head.

\section{INTRODUCTION}

Direct support staff are very important agents in the social environment of people with intellectual disabilities who show challenging behaviour. This is especially the case for people with severe or profound intellectual disabilities, who are very dependent on staff support for several aspects of their daily functioning (Lippold and Burns, 2009; Lunsky, 2008). Many authors have stated that staff behaviour often plays a role in the development and maintenance of challenging behaviour (e.g. Hastings and Remington, 1994). Staff reactions towards challenging behaviour are influenced by a combination of behavioural and cognitive factors (Campbell and Hogg, 2008). According to Hastings (2005), a third factor, namely staff wellbeing and emotions can be added.

Firstly, in the past and for a long time, only the behavioural factor was used to explain staff responses to challenging behaviour (Campbell and Hogg, 2008). This is mostly discussed in the context of reinforcement hypotheses (e.g. Hall et al., 2003; Iwata et al., 1994; Oliver, 1995; Passey and Feldman, 2004; Thompson and Iwata, 2001). These hypotheses assume that staff members positively reinforce challenging behaviour by providing attention or tangibles to the client and negatively reinforce challenging behaviour 
by taking away something the client does not like. Secondly, there has been a general assumption that staff beliefs about problem behaviour have impact on the way in which staff behave towards individuals who show such behavior (Hastings, 2005). Campbell and Hogg (2008) consider beliefs about what challenging behaviour is, what causes it, and how it best can be treated, as the cognitive factor that governs reactions towards challenging behaviour. Finally, at present, more and more attention is given to the psychological effects of challenging behaviours on others (Hastings, 2002). There is already some evidence about the influence of staff psychological wellbeing and staff psychological resources on staff reactions towards challenging behaviour but many relations in this context remain unclear. Staff psychological wellbeing encloses stress, burnout, and mental health (Hastings, 2005). Although challenging behaviour may well be stressful for staff, evidence of an association between challenging behaviour and stress is not yet considered very reliable because this association can also be accounted for by other factors, for example organizational factors (Hastings, 2002). One big problem in the existing research is that no direct measurement of staff exposure to challenging behaviours is included (Hastings, 2002). A final variable that has been studied a lot, are the emotional reactions of staff members towards challenging behaviour. Because of the aversive property of challenging behaviour, one can expect negative emotional reactions in staff members (Hastings, 2005). The majority of the studies about emotional reactions indicated that staff members indeed felt particularly fear, anger, sadness, and frustration among other emotions (Bromley and Emerson, 1995; Raczka, 2005; Whittington and Burns, 2005). However, sometimes staff members reported to feel also positive emotions when working with clients who show challenging behaviour (Bell and Espie, 2002). These emotional reactions may in turn influence staff behaviour towards challenging behaviour.

In this study, we wanted to focus in the first place on staff member's emotional experiences of challenging behaviour. This variable encompasses many concepts that are not yet clear and that need to be studied using direct measurement of staff exposure to challenging behaviours (Hastings, 2002). The general aim of this study was to investigate 
what staff members experience emotionally during or just after the challenging behaviour of people with severe or profound intellectual disabilities. We limited our research to clients with severe or profound intellectual disabilities because we thought that it is very important to distinguish between different levels of intellectual disabilities. Depending on the level of intellectual disability, challenging behaviour may have a totally different function and expression, and elicit different staff reactions and emotions (Borthwick-Duffy, 1994; Emerson, 2001). Moreover, in general, challenging behaviours are positively correlated with the degree of intellectual disability (Emerson, 2001). Furthermore, because these individuals are more dependent on their environment, the relationship between clients and staff in this subpopulation is even more important compared with persons from the whole range of intellectual disability. Furthermore, we tried to use a new method. In the past, questionnaires have often been used to study staff emotions (e.g. Bailey et al., 2006; Hastings, 1997; Hastings et al., 1995; Hill and Dagnan, 2002; Jones and Hastings, 2003). Because of the limited response options staff have in questionnaires, this may not be the most adequate method to study emotions more thoroughly (Smith, 1995). Wanless and Jahoda (2002) stated that these measures do not allow the evaluation of the relationship between staff's cognitive, emotional, and behavioural reactions to the person. Interviews can offer greater scope for addressing these issues. In previous studies, interviews have already been used in this research field but recalling real incidents of challenging behaviour and vignettes were mostly used as a starting point for the interviews (Cudré-Mauroux, 2010; Hastings, 1995; Jahoda and Wanless, 2005; Noone et al., 2006, Wanless and Jahoda, 2002; Whittington and Burns, 2005; Wilcox et al., 2006). Wanless and Jahoda (2002) compared the use of descriptive vignettes and the recall of real incidents in their examination of cognitive and emotional staff responses to aggression. The use of vignettes was found equivocal in comparison with using real incidents. In response to real incidents, stronger emotional responses and more negative evaluations of the clients and their behaviour were evoked and the researchers noticed that staff perceptions of the real clients were significantly associated with their cognitive and emotional reactions to the clients' behaviour, a result that was not 
Staff emotional reactions and experiences towards challenging behaviour

present when using vignettes. However, having to remember incidents still implies the disadvantage that the researcher has no idea about the situations that are recalled. It may happen that staff members only recall extreme instances of difficult behaviour (Jahoda and Wanless, 2005; Noone et al., 2006). Showing staff members examples of their own behaviour by presenting them video recordings of their interaction with the client who is showing challenging behaviour and interviewing them, is a method that meets the above mentioned limitations. In this way, it is not necessary that staff remember situations in which challenging behaviour occurred neither vignettes or descriptions of anonymous clients have to be used. In our study, the interventions that staff members used towards challenging behaviour were presented in video episodes, which gave the opportunity to discuss these interventions with staff members. Summarizing, we wanted to study staff emotions and emotional experiences towards challenging behaviour by discussing their own interaction with a client who is showing challenging behaviour.

\section{METHOD}

\section{Procedure}

Twenty-eight settings in the Dutch speaking part of Belgium specialized in providing care to individuals with severe or profound intellectual disabilities were contacted. We asked if they were willing to film a client - staff member dyad in situations in which the client was presenting challenging behaviour. We asked to film three different situations and set a deadline of a month to collect all recordings. The staff members were asked to agree to participate in the observation study and the following interview session wherein the recordings were shown and questions were asked about their emotions, beliefs, and reactions towards challenging behaviour. The staff members had to have worked with the client for more than six months. Clients had a severe or profound intellectual disability and had to show at least one type of the following challenging behaviours: self-injurious behaviour, stereotyped behaviour, and/or aggressive/destructive behaviour. A severe intellectual disability was defined as an IQ between 20 and 40 or a developmental age 
Staff emotional reactions and experiences towards challenging behaviour

between two and four years; profound intellectual disability was defined as an IQ below 20 or a developmental age below two years.

Furthermore, a focal person, typically the psychologist of the team, received a questionnaire about the client's demographic data and setting information, and the consent form to ask permission to the client's parents or legal guardian. Staff members were asked for some demographic information by a questionnaire that was filled in before the interview took place. Ten settings agreed to participate, of which two settings selected two client-staff member dyads. In total, twelve dyads were willing to participate. The research design was approved by the university's ethical commission.

When we received the recordings, we examined them and selected three episodes out of all the recordings for each client - staff member dyad, considering following criteria: (1) we selected as many different situations as possible for each dyad, (2) we selected situations in which a clear interaction between staff member and client was present, (3) preferably no bathroom situations were selected, and (4) we selected as much as possible well-defined situations with a clear beginning and end. The episode duration varied from 44 seconds to 7 minutes and 22 seconds. For one client - staff member dyad, some of the recordings came short of the presupposed conditions because only the client and not the staff member was seen on these recordings. However, because the staff member was actually present in the two situations, we still decided to use these recordings because they were suitable as basis for the related questions. Afterwards, we contacted the focal person and arranged visits with the staff members involved. As the staff members had to remind their emotional experiences as well as possible, we tried to arrange the interviews as quick as possible. For most of the staff members, the interviews took place within three weeks after we received the recordings. The staff members were interviewed in the settings in a staff room or another quiet room. The interviews were tape-recorded with the consent of the interview partner and the length of the interviews ranged from about 20 minutes to over one hour. 
Staff emotional reactions and experiences towards challenging behaviour

\section{Participants}

The participants in this study were 12 direct care staff working in 10 different services for people with intellectual disabilities.

The ages of the staff members ranged from 22 to 41 years ( mean $=30.09 ; S D=6.20$ ) and the majority of participants were female $(n=9)$. Concerning educational background, seven staff members had completed secondary school, and five staff members had completed three years of higher education. All staff members completed education in the field of (ortho)pedagogical sciences. Their experience in working with people with intellectual disabilities ranged from one to 20 years (mean $=8.88$; $S D=6.11$ ), with people with severe or profound intellectual disabilities from one to 20 years (mean $=7.79$; $S D=5.25$ ) and with the particular client participating in the study from a half to nine years (mean $=3.96$; SD $=2.73$ ). Most participating staff $(n=10)$ worked full-time, and two staff members worked part-time.

Staff members were filmed in interaction with one client and afterwards interviewed about their perceptions about the challenging behaviour of that client. The twelve clients' ages ranged from 12 to 48 years $($ mean $=27.42 ; S D=11.14$ ). Seven clients were male. Four clients had a severe intellectual disability and eight of them a profound intellectual disability. The majority $(n=11)$ of the clients lived in a residential setting; one client lived in a semi-boarding school. Their stay in the setting varied from six to 37 years (mean $=15.08$; SD $=7.93$ ) and in their current group from a half to 22 years (mean $=8.16 ; \mathrm{SD}=6.02$ ). Seven clients always stayed in the setting, while five clients only lived there during weekdays. The group size varied from five to 10 persons (mean $=8.08$; $S D=1.68$ ). An overview of the challenging behaviour that was shown by the clients in each episode is presented in Table I. In 10 episodes, only aggressive/destructive behaviour was shown, in nine episodes only stereotyped behaviour was shown, and in five episodes, only self-injurious behaviour was shown. A combination of aggressive/destructive behaviour and stereotyped behaviour was shown in four episodes, a combination of aggressive/destructive behaviour and self-injurious behaviour was shown in six episodes, and a combination of stereotyped behaviour and self- 
injurious behaviour was shown in one episode. And finally, in one episode the three types of challenging behaviour were shown.

\author{
Insert Table I here
}

\title{
Materials
}

The interview

The current study is part of a larger interview study about staff member's perception towards challenging behaviour. After each of the three situations, certain specific openended questions were asked, but afterwards also general questions about the challenging behaviour and staff's perception regarding this challenging behaviour were asked by means of a semi-structured interview (see Appendix 1). For the current study, we only focused on answers regarding how staff members felt and what they thought during and after the challenging behaviour and on their emotional experiences towards the client. The questions were used to stimulate a dialogue. For one client-staff member dyad, the episodes with situations in which the client was showing challenging behaviour were sufficiently similar, that all three were shown successively and afterwards all the questions were asked just once.

\section{Data analysis}

To analyse the interviews, we used qualitative content analysis (Elo and Kyngäs, 2008; Mostyn, 1985), particularly the inductive approach. First of all, the tapes were transcribed. We decided that the units of analysis exist of paragraphs or sentences that contain one idea, episode, or piece of information. For this study, we only selected the units that referred to emotional experiences. We developed a category system, during an open coding strategy (Elo and Kyngäs, 2008). The written material was read through and categories were freely generated. Afterwards, some smaller categories were grouped under higher order headings. One unit of analysis could contain more than one type of emotional experience and consequently more than one coding category. To ensure the accuracy of this system, randomly selected samples of the interviews were also coded by a second 
independent rater who used the developed category system. In Table II, you can find all the categories that were used in this study.

\section{Insert Table II here}

\section{Reliability}

The reliability scores were based on the units of analysis that contain reactions concerning emotions or emotional experiences. $33 \%$ of all the administered interviews $(n=$ 4) were coded by a second person to obtain a measure of inter-rater reliability. She used the same category system with the same definitions and rules.

To calculate the inter-rater reliability, we used the same method as Hastings (1995) and Cudré-Mauroux (2010). The extent of agreement between the two coders was computed using a percentage agreement index formula ([agreements/[agreements+disagreements]] $\mathrm{x}$ $100 \%)$. An agreement was defined as when the same category or categories were attached to the same unit of analysis. Agreement ranged between $70 \%$ and $93 \%$ (mean $81 \%$ ). All disagreements between the two raters were resolved by discussion.

\section{RESULTS}

All staff emotional experiences towards challenging behaviour were subdivided in 10 higher order categories. In Table II, you can find an overview of all categories and how many times these categories were coded. Sometimes staff members referred to feelings that were felt in the past but not anymore now, that is why the frequency column is subdivided for present and past. In the following overview, each higher order category is illustrated with a meaningful quote. By reproducing the quotes, we tried to stay as close as possible to the literally spoken words of the staff members.

Three big higher order categories came forward from the data. First of all, rather negative emotions or emotional experiences were reported: feeling stressed, frustrated, anger, afraid, bad, nervous, irritated, uncertain, impotent, insecure, inner pain for him/her, feeling that you failed, and losing patience. Staff members felt frustrated for example because they could not stop the challenging behaviour, they could not help the client or could 
not find a solution for the client's problem. The same ideas were mentioned by other staff members, referring to reasons for their feeling of impotence. Some staff members told they did felt bad, but not always because of themselves. They referred to the inner pain they felt for the client.

"I think that it is always a pity that she hurt herself like that, she always begins to slap herself in her face... I do not know why she always slaps herself, it is sometimes awful..."

In contrast with positive emotions or emotional experiences, sometimes negative emotions or emotional experiences were situated in the past $(n=15)$. For example, some staff members told that they were afraid of a client when he or she was showing challenging behaviour during the first period they worked with that client, when they did not know the client very well and that this feeling disappeared when they got to know the client much better.

Secondly, positive emotions or emotional experiences were mentioned: feeling calm, hopeful, good/satisfied, relieved, confident, and secure. Staff members felt good/satisfied or relieved because of the experience that the activity could go on or ended well and felt confident because they managed to interrupt the challenging behaviour and because of their experience with the client.

"But when it went very well, then you are also very satisfied and you express it to the client... and she is also rather sensitive to this."

The emotion of feeling calm was often linked to the actions staff members had to carry out. They mentioned that they learned that staying calm is the best reaction in difficult situations.

Thirdly, staff members often referred to the absence of negative emotions or to rather neutral feelings: feeling not bad, not frustrated, not disappointed or angry, no fear, no stress, not insecure, and feeling rather neutral. Most staff members felt not insecure when the client was showing challenging behaviour. Two staff members mentioned that they felt insecure in the past but not anymore. In addition, staff members referred more frequently to feelings of no stress in comparison with answers referring to feelings of stress.

"No, I am not feeling stress, you learn to handle it en to give it place. With ten different clients, then you know for every client what can happen or what he or she can do. Knowing this, is important in supporting them, but it brings no stress along." 
Staff emotional reactions and experiences towards challenging behaviour

Examples of rather neutral feelings are: I only have to change my tack $(n=2)$, I have to accept it; it is the way it is $(n=5)$, feeling neutral $(n=4)$, and I can stand a lot $(n=1)$.

"What I feel afterwards, when the situation is finished? Goh, yes, it maybe is strange to say but in the long turn you become also a little used to it and it does not really affect you".

Furthermore, staff members often referred to particular emotions when the challenging behavior occurred several times a day or during a whole week.

"If it happens one or two weeks on end, in the long run, you are done; you are really done."

Very often staff members mentioned their colleagues and the help they received from them. Except for one staff member who referred to a situation in which she was angry at her colleagues about a certain agreement, all other reactions in this context were positive. Staff members referred to experiences of being able to count on their colleagues, searching for solutions or interventions together, and relieving their feelings after a difficult situation.

"We, actually, have each other. The colleagues, that is a good team. This is important if you work with these kind of clients, that you can count on each other, that you can talk about it with each other."

22 reactions were linked to the general view of the client and whether the staff members were capable to view the client next to the challenging behavior. Most of these reactions included the experience that staff members were able to view the client apart from his/her challenging behaviour $(n=13)$, whether in nine reactions staff members referred to the experience that they linked the client with the challenging behaviour, certainly in periods in which the client was showing challenging behaviour a lot.

"I try to see him apart from the challenging behavior. He is more than the challenging behaviour alone. I try for myself to give him a positive self-image, to explicitly underline little things that he does well. So, I can see him apart from the challenging behaviour."

Staff members reported that they were satisfied with their intervention $(n=29$ (present) and $n=1$ (past)) or were positive about the intervention or action that was agreed upon in the team they worked with $(n=4)$, while other staff members were rather discontent with certain agreements about interventions $(n=3)$ or with their own intervention ( $n=6$ (present) and $n=1$ (past)) in a particular situation. 
"When it is over, when it actually is too late, I am considering: 'What have I done?', 'I rather would have stayed calm. Then it would have gone better'."

Furthermore, it was remarkable that staff members very often expressed what they thought during the challenging behaviour and what kind of thoughts were playing in their head. First of all, staff members were often thinking about certain actions they had to carry out. Many staff members answered that they were busy with the actions inherent to the activity (e.g. trying to wash a client as quickly as possible or helping a client to drink his water, ...).

"At that moment, the emotion self is like 'I want him to go to the activity (outside the building)" and trying to listen to his needs. I was not afraid, emotional, or rebellious at that moment."

Secondly, staff members' thoughts involved questions or uncertainties. Staff members reported that they were thinking about what they had to do at that moment and what the most adequate reactions were ( $n=18$ (present) and $n=3$ (past)). Also questions about why this was happening $(n=8)$, about what would happen next $(n=6)$, and about the meaning of the challenging behaviour $(n=3)$ were occupying staff members' mind when the client was showing challenging behaviour.

"I am asking myself a lot: 'what am I doing wrong?', 'why does this happen?', I ask myself many questions and every time the same question 'why does this happen?'."

Some staff members reported that they needed a pause after the challenging behaviour, and that they kept thinking about the challenging behaviour, sometimes even when they were at home.

"Even when I am going home afterwards. If he has showed very serious challenging behaviour, I am still thinking about it when I am at home. It already took me many sleepless nights. A thing like that gets you."

However, other staff members were not thinking about the challenging behaviour

afterwards and mentioned that they kept going on.

"I am not thinking about it afterwards. That is part of our job. You know that you are working in a group with people who are showing challenging behaviour and, I think, I have always said, our children are not aware of who they beat, they have an intellectual disability and they have to come out with their challenging behaviour. It does not matter if it is me or someone else who is standing there. It has to come out." 
Finally, there were several types of reactions that are rather difficult to classify under one broader category: feeling physically tired $(n=7)$, being attentive $(n=4)$, waiting or having patience ( $n=5$ (present) and $n=1$ (past)).

"During the challenging behaviour, I was waiting. I was thinking 'it will turn out all right', he was calm, he was rather well-disposed as he began to smile."

\section{DISCUSSION AND PRACTICAL APPLICATION}

The goal of this study was to examine staff emotions and emotional reactions on the basis of the experiences of staff members themselves.

Although in the literature mostly negative emotions were related to challenging behaviours (e.g. Bromley and Emerson, 1995; Jenkins , 1997; Raczka, 2005; Whittington and Burns, 2005), in our questionnaire research (Author Citation 1), but also in other previous research, positive attitudes such as high confidence, empathy, and low levels of feelings of excitement and fear were also reported by staff members (Bell and Espie, 2002). Also in this study, the absence of negative emotions and positive emotions were mentioned a lot. Notwithstanding, many negative emotions were referred to and sometimes the rather negative feelings were that strong that it was difficult for some staff members to see the client next to his/her challenging behaviour. This is an important result that asks for sensitization and training of staff members because one has to keep in mind that staff members have to treat a client in a way that respects him or her as a person and his or her development and quality of life. According to the rather neutral feelings that were mentioned by several staff members, we want to point out the risk of habit formation. If you accept a situation as such without looking to other solutions, nothing will change anymore and the challenging behaviour will remain.

Next to this, it became clear that an indication of time is important in this context. Very often staff members reported particular emotions like feeling irritated or impatient when the challenging behaviour occurred several times a day or during a whole week, which caused firmer or angrier behaviour. Secondly, staff members also differentiated between emotions 
Staff emotional reactions and experiences towards challenging behaviour

they felt in the past and current emotions. Negative emotions often faded away because of the knowledge and the experiences they acquired concerning the client and his or her challenging behaviour.

Fortunately, much more staff members were satisfied with their interventions or actions regarding to the challenging behaviour in comparison with staff members that were not satisfied with their interventions or actions. Obviously, we are unable to pronounce upon the quality of these interventions or actions.

Staff members often referred to thoughts that cross their mind during or after the challenging behaviour. These thoughts often imply actions that have to be undertaken towards the client and questions or uncertainties regarding the challenging behaviour. Furthermore, staff members sometimes keep thinking about an incident, even a long period after the challenging behaviour took place. Although they were mentioned in answers on questions about emotions, these thoughts seem to belong to staff beliefs. They are very important for staff members and will influence their reactions to challenging behaviour. Therefore, next to the attributions that have mostly been studied in the past, research about beliefs towards challenging behaviour should also focus on these kind of thoughts.

Next to those that were already mentioned, there are some other limitations in this study design. No distinction was made between several types of challenging behaviour because of two main reasons. First of all, some clients were showing more than one type of challenging behaviour and it was difficult to tease out what staff members had said about the several types of challenging behaviour. Furthermore, because too few answers would remain for each type of challenging behaviour, it would not be possible to make relevant conclusions. Nevertheless, this would be a very relevant issue to investigate in further research. Furthermore, although using a camera to obtain recordings of staff members and clients who show challenging behaviour has many advantages, a disadvantage is the possible influence of the camera. However, Jordan and Henderson (1995) claim that people habituate to the camera surprisingly quickly and that the presence of a camera is likely to fade out of awareness quite rapidly. In this study, two staff members noticed that it could be 
that the client had showed challenging behaviour as a reaction to the camera. Furthermore, the results of this study have to be treated carefully; findings coming from this sort of qualitative study are not generalizable to a broad population. Nevertheless, the results generate new perspectives and issues to deal with in this research domain, yielding many suggestions for further research. As already mentioned, we think that it is important to examine positive emotions and rather neutral feelings next to negative emotions and possible consequences of these feelings, to take into account if challenging behaviour just happened once or was shown more times a day or during a whole week, and to consider staff members' thoughts in research about staff beliefs towards challenging behaviour.

In line with previous research in this domain, the results of this study indicate that clients' challenging behaviour has a great impact on staff members that should not be underestimated. The staff members reported negative emotions, doubts, concerns, and have many questions when dealing with challenging behaviour. Of course it is important that this is recognized and handled by psychologists, managers, or directors who are supporting staff members. Furthermore, also the support between staff members seems very important and got an important place in the answers because staff members are feeling more calm and secure knowing that they can count on their colleagues for help. A good working team seems indispensable in working with clients who show challenging behaviour.

It can be advisable for staff members to consider their own emotions and emotional experiences and the influence they have on their reactions. This could result in reactions that are more adjusted to the client's needs. In the past, specific interventions dealing with increasing staff satisfaction and staff confidence, understanding the causes of challenging behaviour, and gaining knowledge about their reactions were already applied (e.g. Allen and Tynan, 2000; Grey et al., 2002; McDonnell, 1997; Singh et al., 2006). Furthermore, we suggest a specific method to carry out such interventions: working with video recordings and observations. Using this method can be very helpful because sometimes staff members react in ways that they are not aware of. Embregts (2002a; 2002b; 2003) evaluated the effectiveness of using video (and graphic) feedback for staff members working with children 
Staff emotional reactions and experiences towards challenging behaviour

with mild intellectual disabilities who show inappropriate behaviour and demonstrated a clear improvement in staff behaviour. Furthermore, the staff members were satisfied with the training and rated the use of video feedback as highly acceptable (Embregts, 2002b). We think that not only in the context of discussing staff members' behaviour but also in the context of making emotions and emotional experiences subject of discussion, this method can be very useful. Also in the current study, the staff members were of the opinion that it was very interesting to reflect on their own emotions by means of video recordings.

\section{ACKNOWLEDGEMENTS}

The authors wish to thank all the staff members, Kristien Hermans, Soetkin Heylen, Ine Hostyn, and Anneleen Penne for their contribution to this manuscript.

\section{REFERENCES}

Allen, D. and Tynan, H. (2000). Responding to aggressive behaviour: Impact of training on staff members' knowledge and confidence. Mental Retardation, 38, 97-104.

Bailey, B. A., Hare, D. J., Hatton, C., and Limb, K. (2006). The response to challenging behaviour by care staff: Emotional responses, attributions of cause and observations of practice. Journal of Intellectual Disability Research, 50, 199-211.

Bell, D. M. and Espie, C. A. (2002). A preliminary investigation into staff satisfaction, and staff emotions and attitudes in a unit for men with learning disabilities and serious challenging behaviours. British Journal of Learning Disabilities, 30, 19-27.

Borthwick-Duffy, S. A. (1994). Epidemiology and prevalence of psychopathology in people with mental retardation. Journal of Consulting and Clinical Psychology, 62, 17-27.

Bromley, J. and Emerson, E. (1995). Beliefs and emotional reactions of care staff working with people with challenging behaviour. Journal of Intellectual Disability Research, 39, 341-352. 
Campbell, M. and Hogg, J. (2008). Impact of training on cognitive representation of challenging behaviour in staff working with adults with intellectual disabilities. Journal of Applied Research in Intellectual Disabilities, 21, 561-574.

Cudré-Mauroux, A. (2010). Staff attributions about challenging behaviours of people with intellectual disabilities and transactional stress process: a qualitative study. Journal of Intellectual Disability Research, 54, 26-39.

Elo, S. and Kyngäs, H. (2008). The qualitative content analysis process. Journal of Advanced Nursing, 62, 107-115.

Embregts, P. J. C. M. (2002a). Effect of resident and direct-care staff training on responding during social interactions. Research in Developmental Disabilities, 23, 353-366.

Embregts, P. J. C. M. (2002b). Effects of video feedback on social behaviour of young people with mild intellectual disability and staff responses. International Journal of Disability, Development and Education, 49, 105-116.

Embregts, P. J. C. M. (2003). Using self-management, video feedback and graphic feedback to improve social behaviour of youth with mild mental retardation. Education and Training in Developmental Disabilities, 38, 283-295.

Emerson, E. (2001). Challenging Behaviour. Analysis and intervention in people with severe intellectual disabilities (2nd ed.). Cambridge: University Press.

Grey, I. M., McClean, B., and Barnes-Holmes, D. (2002). Staff attributions about the causes of challenging behaviours. Effects of longitudinal training in multi-element behaviour support. Journal of Learning Disabilities, 6, 297-312.

Hall, S., Thorns, T., and Oliver, C. (2003). Structural and environmental characteristics of stereotyped behaviors. American Journal on Mental Retardation, 108, 391-402.

Hastings, R. P. (1995). Understanding factors that influence staff responses to challenging behaviours: an exploratory interview study. Mental Handicap Research, 8, 296-320.

Hastings, R. P. (1997). Measuring staff perceptions of challenging behaviour: the Challenging Behaviour Attributions Scale (CHABA). Journal of Intellectual Disability Research, 41, 495-501. 
Staff emotional reactions and experiences towards challenging behaviour

Hastings, R. P. (2002). Do challenging behaviors affect staff psychological well-being? Issues of causality and mechanism. American Journal on Mental Retardation, 107, 455467.

Hastings, R. P., (2005). Staff in special education settings and behaviour problems: Towards a framework for research and practice. Educational Psychology, 25, 207-221.

Hastings, R. P. and Remington, B. (1994). Rules of engagement: Toward an analysis of staff responses to challenging behaviour. Research in Developmental Disabilities, 15, 279298.

Hastings, R. P., Remington, B., and Hopper, G. M. (1995). Experienced and inexperienced health care workers' beliefs about challenging behaviours. Journal of Intellectual Disability Research, 39, 474-483.

Hill, C. and Dagnan, D. (2002). Helping, attributions, emotions and coping style in response to people with learning disabilities and challenging behaviour. Journal of Learning Disabilities, 6, 363-372.

Iwata, B. A., Dorsey, M. F., Slifer, K. J., Bauman, K. E., and Richman, G. S. (1994). Toward a functional analysis of self-injury. Journal of Applied Behavior Analysis, 27, 197-209.

Jahoda, A. and Wanless, L. K. (2005). Knowing you: The interpersonal perceptions of staff towards aggressive individuals with mild to moderate intellectual disabilities in situations of conflict. Journal of Intellectual Disability Research, 49, 544-551.

Jenkins, R., Rose, J., and Lovell, C. (1997). Psychological well-being of staff working with people who have challenging behaviour. Journal of Intellectual Disability Research, 41, 502-511.

Jones, C. and Hastings, R. P. (2003). Staff reactions to self-injurious behaviours in learning disability services: Attributions, emotional responses and helping. British Journal of Clinical Psychology, 42, 189-203.

Jordan, B. and Henderson, A. (1995). Interaction Analysis: Foundations and practice. Journal of the Learning Sciences, 4, 39-103. 
Lippold, T. and Burns, J. (2009). Social support and intellectual disabilities: A comparison between social networks of adults with intellectual disability and those with physical disability. Journal of Intellectual Disability Research, 53, 463-473.

Lunsky, Y. (2008). The impact of stress and social support on the mental health of individuals with intellectual disabilities. Salud Publica de Mexico, 50, 151-153.

McDonnell, A. (1997). Training care staff to manage challenging behaviour: An evaluation of a three day training course. The British Journal of Developmental Disabilities, 43, $156-$ 162.

Mostyn, B. (1985). The content analysis of qualitative research data: A dynamic approach. In: Brenner, M., Brown, J., and Canter, D. (Eds.). The research interview. Uses and Approaches (pp. 115-145). London: Academic Press.

Noone, S. J., Jones, R. S. P., and Hastings, R. P. (2006). Care staff attributions about challenging behaviors in adults with intellectual disabilities. Research in Developmental Disabilities, 27, 109-120.

Oliver, C. (1995). Annotation: self-injurious behaviour in children with learning disabilities: Recent advances in assessment and intervention. Journal of Child Psychology and Psychiatry, 30, 909-927.

Passey, J. and Feldman, M. (2004). Descriptive analysis of parent-child interactions in young children with or at risk for developmental delay. Behavioral Interventions, 19, 233-246.

Raczka, R. (2005). A focus group enquiry into stress experienced by staff working with people with challenging behaviours. Journal of Intellectual Disabilities, 9, 167-177.

Singh, N. N., Lancioni, G. E., Winton, A. S. W., Curtis, W. J., Wahler, R. G., Sabaawi, M., Singh, J., and McAleavey, K. (2006). Mindful staff increase learning and reduce aggression in adults with developmental disabilities. Research in Developmental Disabilities, 27, 545-558.

Smith, J. A. (1995). Semi-structured interviewing and qualitative analysis. In: Smith, J.A., Harré, R., and Van Langenhove, L. (Eds). Rethinking methods in psychology (pp. 926). London: Sage. 
Thompson, R. H. and Iwata, B. A. (2001). A descriptive analysis of social consequences following problem behavior. Journal of Applied Behavior Analysis, 34, 169-178.

Wanless, L. K. and Jahoda, A. (2002). Responses of staff towards people with mild to moderate intellectual disability who behave aggressively: A cognitive emotional analysis. Journal of Intellectual Disability Research, 46, 507-516.

Whittington, A. and Burns, J. (2005). The dilemmas of residential care staff working with the challenging behaviour of people with learning disabilities. British Journal of Clinical Psychology, 44, 59-76.

Wilcox, E., Finlay, W. M., and Edmonds, J. (2006). 'His brain is totally different': An analysis of care-staff explanations of aggressive challenging behaviour and the impact of gendered discourses. British Journal of Social Psychology, 45, 197-216.

\section{Original reference referring to the work of any of the authors}

\section{Author Citation 1}

Lambrechts G., Kuppens S., and Maes B. (2009). Staff variables associated with the challenging behaviour of clients with severe or profound intellectual disabilities. Journal of Intellectual Disability Research, 53, 620-632. 
Staff emotional reactions and experiences towards challenging behaviour

Table I

The type of challenging behaviour shown by the clients per episode

\begin{tabular}{|c|c|c|c|c|c|c|c|c|c|}
\hline & \multicolumn{3}{|c|}{ Episode 1} & \multicolumn{3}{|c|}{ Episode 2} & \multicolumn{3}{|c|}{ Episode 3} \\
\hline & $A / D B$ & St. B & S-I B & $A / D B$ & St. B & S-I B & $A / D B$ & St. B & S-I B \\
\hline Client 1 & $\mathrm{x}$ & & & $\mathrm{x}$ & & & $\mathrm{x}$ & & \\
\hline Client 2 & $x$ & $x$ & & $x$ & $x$ & & $x$ & $x$ & \\
\hline Client 3 & & $x$ & & & $x$ & & & $x$ & \\
\hline Client 4 & $x$ & & $x$ & $x$ & & $x$ & $x$ & & $x$ \\
\hline Client 5 & $x$ & & & $x$ & $x$ & $x$ & $x$ & $x$ & \\
\hline Client 6 & $x$ & & $x$ & $x$ & & $x$ & & & $x$ \\
\hline Client 7 & & & $x$ & & $x$ & $x$ & $x$ & & \\
\hline Client 8 & $x$ & & & $x$ & & & $x$ & & \\
\hline $\begin{array}{l}\text { Client } 9 \\
\text { Client }\end{array}$ & $x$ & & & $x$ & & & $x$ & & $x$ \\
\hline $\begin{array}{l}10 \\
\text { Client }\end{array}$ & & & $x$ & & & $x$ & & & $x$ \\
\hline $\begin{array}{l}11 \\
\text { Client }\end{array}$ & & $x$ & & & $x$ & & & $x$ & \\
\hline 12 & & $x$ & 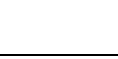 & . & $x$ & 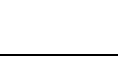 & & $x$ & \\
\hline
\end{tabular}


Table II

Categories and the frequency of appearance

\begin{tabular}{cc} 
& \multicolumn{2}{c}{ Frequency } \\
Category & Present Past
\end{tabular}

1. Negative emotions or emotional experiences

$\begin{array}{lrr}\text { Feeling stressed } & 5 & 2 \\ \text { Feeling frustrated } & 18 & 1 \\ \text { Feeling anger } & 8 & 0 \\ \text { Losing patience } & 3 & 2 \\ \text { Feeling afraid } & 2 & 5 \\ \text { Feeling bad } & 2 & 0 \\ \text { Feeling nervous } & 8 & 0 \\ \text { Feeling irritated } & 1 & 0 \\ \text { Feeling uncertain } & 7 & 1 \\ \text { Feeling impotent } & 14 & 1 \\ \text { Feeling insecure } & 1 & 2 \\ \text { Feeling inner pain for him/her } & 10 & 0 \\ \text { Feeling that you failed } & 2 & 1 \\ \text { Total Negative emotions or emotional experiences } & 81 & \mathbf{1 5}\end{array}$

2. Positive emotions or emotional experiences

Feeling calm

Feeling hopeful

$17 \quad 0$

Feeling good/satisfied

10

Feeling relieved

$7 \quad 0$

Feeling confident

2

Feeling secure

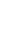
5 0

Total Positive emotions or emotional experiences

3. Absence of negative emotions / neutral feelings

Feeling not bad

Feeling not frustrated

Feeling not disappointed or angry

Feeling no fear

Feeling no stress

Feeling not insecure

Rather neutral feelings

Total Absence of negative emotions / neutral feelings

4. Particular emotions when the challenging behavior occurred more than once

5. Reference to their colleagues and the help they recieve from them

6. General view of the client

7. Reference to interventions

Satisfied with interventions or actions

Discontent with interventions or actions

$33 \quad 1$

8. Thougths

About certain actions 
Staff emotional reactions and experiences towards challenging behaviour

Questions or uncertainties

9. Feelings that may or may not linger afterwards

Thinking about the challenging behaviour afterwards

110

Not thinking about the challenging behaviour afterwards

10. Other feelings 


\section{Appendix 1}

Semi-structured interview

After each episode, the following questions were asked:

- Can you give me an idea of the situation? What happened before this episode?

- Who was present at that moment? What kind of activity was going on?

- What did you do just before the challenging behaviour began?

- How did you feel:

- Just before the interaction?

- During the challenging behaviour?

- When the challenging behaviour had stopped?

- What emotion was strongest during the occurrence of the challenging behaviour?

- What do you think caused the challenging behaviour?

- Is there a particular reason that stands out for you or are the multiple reasons equally strong in your opinion?

- What exactly did you do and why?

- If you were in this situation again, would you again react as you did or would you apply another intervention?

\section{After running through the three episodes, more general questions were asked:}

- What type of challenging behaviour does this client show?

- Does he/she often show this behaviour? Are these episodes 'typical' moments in which the challenging behavior occurs or does it also occur at other moments or is it difficult to foresee when the challenging behaviour will occur?

- Do you often feel like this when the client shows challenging behaviour? (name the emotions that were referred to after looking at the episodes)

- Determine these feelings how you feel towards this client generally?

- Determine these feelings how you react towards the challenging behaviour?

- How do you consider this challenging behaviour? Is it important for you? Is it a source of stress?

- Dominates this challenging behaviour the image you have of the client or can you consider him/her apart from the challenging behaviour?

- Do you sometimes feel insecure?

- Are there, other than the listed causes, other causes for this client's challenging behaviour?

- Do you use other interventions?

- Are you happy with your own interventions or would you prefer sometimes to react different?

- Do there exist a common vision on challenging behaviour within your setting?

- Do there exist some agreements about the concrete treatment of this client's challenging behaviour?

- Did you attend some specific training or workshop concerning challenging behaviour? Do you need that? 